\title{
HORIZONTES DE LECTURA EN EL EJEMPLO XI DE EL CONDE LUCANOR
}

\author{
LuIs GaLván \\ Universidad de Navarra
}

\begin{abstract}
El ejemplo XI, «De lo que contesciố a un deán de Sanctiago con Don Yllán, gran maestro de Toledo», es uno de los más celebrados y estudiados de El conde Lucanor. El deán que acude al maestro para aprender la nigromancia es nombrado sucesivamente Arzobispo de Santiago, Obispo de Tolosa, Cardenal y Papa; cada vez es más desagradecido y por fin descortés y hostil con don Yllán; y éste deshace la carrera eclesiástica de su discípulo, que era sólo ilusoria; los dos se encuentran en el mismo momento y lugar en que se conocieron, y el deán es despedido sin contemplaciones. Se han investigado las fuentes de este relato, su estructura y su tejido verbal, su simbolismo y sus versiones modernas ${ }^{1}$. Pero queda una dificultad que no suele abordarse. Hace más de un siglo, Knust anotó que el renunciar al arzobispado de Santiago para ocupar el obispado de Tolosa era, cuando menos, llamativo². En 1972, Devoto destacó a
\end{abstract}

\footnotetext{
1 Ver la bibliografía comentada por Daniel Devoto (Introducción al estudio de Don Juan Manuel y en particular de «El conde Lucanor»: una bibliografia, Madrid, Castalia, 1972, págs. 382-93); sobre el tiempo mágico, ver también Mariano Baquero Goyanes, «Perspectivismo en El conde Lucanorn, Don Juan Manuel: VI centenario, Murcia, Universidad de Murcia, 1982, págs. 27-50 (especialmente págs. 48-50) y Jovita Bobes Naves, «El valor semántico del tiempo en el cuento de don Yllán, de D. Juan Manuel», Archivum, 36, 1986, págs. 163-85; sobre la estructura y la textura verbal, ver John England, " $\measuredangle E t$ non el dia del lodo?": The Structure of the Short Fiction in El Conde Lucanom, Juan Manuel Studies, ed. Ian Macpherson, London, Tamesis, 1977, págs. 69-86 (especialmente págs. 74-77); sobre las versiones modernas: Cristina González, «Don Juan Manuel y Borges: 'El gran maestro de Toledo' y 'El brujo postergado', dos versiones de un ejemplom, Insula, 371, 1977, págs. 1 y 14; Marta Ana Diz, «El mago de Toledo: Borges y Don Juan Manuel», $M L N, 100.2,1985$, págs. 281-97; y Derek W. Lomax, «El conde Lucanor como fuente de comediasm, Teatro del Siglo de Oro: Homenaje a Alberto Navarro González, ed. Victor García de la Concha, Jean Canavaggio, Theo Berchem y María Luisa Lobato, Kassel, Reichenberger, 1990, págs. 367-77.

2 Juan Manuel, El Libro de los enxiemplos del conde Lucanor et de Patronio, ed. Hermann Knust y Adolf Birch-Hirschfeld, Leipzig, Seele, 1900 (reimpr. Ann Arbor, UMI, 1985), págs. 329-30.
}

RFE, LXXXIV, 2004, 2., págs. 285-301 
su vez «el dar el obispado de Tolosa a un arzobispo», pero sólo dedica unas líneas al asunto, suficientes para mostrar que en los setenta años transcurridos apenas había recibido atención ${ }^{3}$. Por último, Ayerbe-Chaux menciona de pasada, y sin aclararlo, «el problema que ha preocupado a algunos, de bajar al deán de arzobispado a obispado» 4 .

En realidad, ese detalle encierra tres cuestiones: si bien la carrera del deán es ascendente en general, zes un ascenso el paso del arzobispado de Santiago al obispado de Tolosa? ¿Es superfluo o significativo ese paso en la carrera? ¿Por qué precisamente Tolosa? Para contestar, es necesaria una hermenéutica adecuada, que haga justicia a ese componente y descubra la estructura narrativa y la relación con la historia implicadas por él ${ }^{5}$.

El acceso a la literatura medieval requiere el disfrute estético de los textos, la percepción de su alteridad respecto del presente, y la aceptación de una validez vinculante en la actualidad, según expone Hans Robert Jauss ${ }^{6}$. Jauss expone el triple carácter de una hermenéutica literaria que responde a las tres facetas de la comprensión, la interpretación y la aplicación, como si fuesen tres lecturas distintas de un mismo texto. La primera lectura es la que percibe estéticamente: avanza de elemento en elemento, proyectando y corrigiendo un todo; al final aprehende una coherencia global, un significado completo, un mundo de ficción y una virtualidad linguística. La segunda lectura se proyecta sobre la totalidad alcanzada en la primera; vuelve sobre alguna pregunta que se dejó abierta, y elabora una respuesta exhaustiva en la interpretación. El resultado es una precisión mayor en el significado y la forma percibidos, a cambio de una limitación por la perspectiva que la pregunta concreta impone al todo. La tercera lectura es de carácter histórico y se destina a fortalecer la alteridad del texto. En ella, la pregunta propia de la segunda lectura, surgida del lector, es sustituida por otra que procede del mundo originario de la obra. Se trata de conocer el texto como respuesta a determinadas expectativas de su tiempo, referentes a la forma litera-

\footnotetext{
${ }^{3}$ Devoto, op. cit., págs. 392-93.

4 Don Juan Manuel, Libro del Conde Lucanor, ed. Reinaldo Ayerbe-Chaux, Madrid, Alhambra, 1983, pág. 144.

${ }^{5}$ Las aproximaciones al ejemplo XI desde el punto de vista de la historia no han enfocado esta cuestión; comp. Reinaldo Ayerbe-Chaux, «El Conde Lucanor»; materia tradicional y originalidad creadora, Madrid, Porrúa Turanzas, 1975, págs. 98-104; Francisco Miranda, «Vn dean de Sanctiago y don Yllan, el maestro de Toledo: Nigromancia e historia en El Conde Lucanom, Revista Canadiense de Estudios Hispánicos, 23.2, 1999, págs. 329-40; José Antonio Mucino Ruiz, «Literatura medieval y criptoanálisis: El 'Exemplo' XI del Conde Lucanon, Palabra $e$ imagen en la Edad Media, ed. Aurelio González, Lillian von der Walde y Concepción Company, México, Universidad Nacional Autónoma de México, 1995, págs. 257-66.

${ }^{6}$ Hans-Robert Jauss, Alteritat und Modemitat der mittelalterlichen Literatur: Gesammelte Aufsätze 1956-1976, München, Fink, 1977, págs. 10-14; y «Der poetische Text im Horizontwandel der Lektiure (am Beispiel von Baudelaires zweitem Spleen-Gedicht)», Romanistische Zeitschrift fir Literaturgeschichte, 4, 1980, págs. 228-74 (especialmente págs. 230-37).
} 
ria o al sentido del mundo histórico. Jauss considera que este tercer paso equivale a la aplicación hermenéutica, al reconocimiento de una verdad vinculante en el texto, porque es el método que asegura el respeto a la alteridad frente al peligro de una modemización ingenua de acuerdo con las expectativas del lector. Lo descubierto, aunque sea antiguo, resultará nuevo para el lector, y podrá contrastar, ampliar y enriquecer sus ideas y gustos. Jauss añade que el orden de estas tres lecturas es metodológico, no temporal; en ocasiones, y sobre todo tratándose de obras lejanas en el tiempo o el espacio, la adquisición de conocimientos históricos será requisito de la mera comprensión estética.

Estas propuestas de método señalan la función de la investigación histórica en una hermenéutica de fundamento filosófico tal como la plantea Hans Georg Gadamer ${ }^{7}$. La comprensión es una suerte de diálogo que desemboca en la fusión de horizontes. Comprender exige acoger un valor de verdad, o al menos una pretensión de verdad. Se trata de dialogar con los textos para que se manifiesten como respuestas a preguntas abiertas en su horizonte. De esta manera se gana el horizonte histórico de las obras, y se puede asegurar su identidad propia, su alteridad respecto del lector. Mediante el diálogo continuado, se produce la fusión de los horizontes de la obra y del lector. Si este proceso queda incompleto, se corren dos peligros: el de subsumir ingenuamente la obra del pasado en el horizonte actual, o el de segregarla confinándola en su propio tiempo, como si ya no contuviese ninguna verdad vinculante. En cualquiera de estos dos casos, la lectura no tiene carácter de experiencia, no modifica ni amplía la conciencia del lector ${ }^{8}$.

De acuerdo con estas ideas, el estudio del ejemplo XI de El Conde Lucanor seguirá los tres pasos esbozados por Jauss. En primer lugar expondré la comprensión global del sentido y de la forma, atendiendo especialmente al papel del obispado de Tolosa. Para asegurar que se trata de una comprensión intersubjetiva, y no una construcción ad hoc, utilizaré como protocolos de lectura, esencialmente, cinco recensiones modernas del cuento, por Baltasar Gracián, Azorín, Jorge Luis Borges, Eduardo Frieiro y Enrique Ánderson Imbert ${ }^{9}$. Luego pasaré

${ }^{7}$ Hans-Georg Gadamer, Verdad y método: fundamentos de una hermenéutica filosofica, trad. Ana Agud Aparicio y Rafael de Agapito, $4^{2}$ ed., Salamanca, Sígueme, 1991 (especialmente págs. 370-77 y 447-48).

8 Gadamer resta importancia al conocimiento histórico en el caso de la literatura: «lo más sensato y aún lo exigido es pensar que el sentido de la poesía [des dichterisches Wortes] se enuncia en lo dicho como tal, sin ninguna adición de saberes ocasionales» (op. cir., pág. 562); lo cierto es que su atención se dirige sobre todo a la lírica moderna, mientras que una obra narrativa y medieval requerirá indudablemente una aproximación más compleja (ver Luis Galván, «El concepto de aplicación en la hermenéutica literarian, Signa: Revista de la Asociación Española de Semiótica, en prensa).

9 Baltasar Gracián, «Agudeza y arte de ingenio», Obras completas, vol. 2, Madrid, Turner, 1993, págs. 305-763; Azorín, «Los valores literarios», Obras escogidas, II: ensayos, Madrid, Espasa-Calpe, 1998, págs. 1019-1252; Jorge Luis Borges, «El brujo postergado», en Historia uni- 
a un sucinto análisis del texto en busca de alguna clave. En tercer lugar, examinaré el cuento a la luz de la historia precedente y contemporánea a él.

\section{COMPRENSIÓN: EL. TODO Y LAS PARTES}

El ejemplo XI está completamente abierto para el primer acceso a las obras medievales: el disfrute estético. Gracián nota el cuento de «muy sazonado» entre todos los que componen el «nunca debidamente alabado libro de $\mathrm{El}$ Conde Lucanons ${ }^{10}$, Borges recuerda que de pequeño lo escuchaba con gusto una $y$ otra vez ${ }^{1 k}$, y un personaje de Ánderson lo considera «el mejor de toda la Edad Media. [...] ¡Y de toda la literatura española!» ${ }^{12}$.

En cuanto al sentido de conjunto y el papel del obispado de Tolosa, hay distintos matices. Gracián interpreta que el cuento «pondera la ingratitud de los que levantados a gran fortuna; se olvidan de sus amigos y aun corresponden con agravios a los mismos que les ayudaron a subir» ${ }^{13}$. Se trata, por tanto, de la historia de un ascenso, que él resume en las etapas de deán, arzobispo de Santiago, obispo de Tolosa, y cardenal y papa, sin prestar atención al paso por Tolosa. Azorín presenta las mismas etapas; por un pequeño añadido, el obispado tolosano recibe los tintes de un justo ascenso: «Ya están todos en Santiago. El arzobispo es un buen arzobispo; todos le quieren; él es bondadoso con todos. [...] Ha vacado el obispado de Tolosa; para esa sede nombra el papa al arzobispo» ${ }^{14}$. Parece que fuese un premio a su bondad o un reconocimiento de su mérito.

Ánderson compendia más la carrera eclesiástica del personaje: «el Arzobispo de Santiago había fallecido y al Deán lo iban a elegir como sucesor [...]. Varias veces, a lo largo de varios años, sucedió lo mismo: el Arzobispo pasó a ser Obispo, Cardenal y Papa; y a cada nueva promoción defraudaba a Don Illán» ${ }^{15}$. El paso de arzobispo a obispo queda en la categoría de «promoción»; por otra parte, no se menciona Tolosa en ningún momento. En esta recensión, por tanto, no hay una dificultad, como en el texto medieval, sino todo un con-

\footnotetext{
versal de la infamia (cito por Prosa completa, vol. 1, Barcelona, Bruguera, 1985, págs. 304-06); Borges redactó una nueva versión para la Antología de la literatura fantástica ( $3^{\mathrm{a}}$ ed., Buenos Aires, Sudamericana, 1967, págs. 220-22); Eduardo Frieiro, «O mágico de Toledon, $O$ alegre arcipreste e outros temas de literatura espanhola, Belo Horizonte, Livraria Oscar Nicolai, 1959, págs. 56-66; y Enrique Ánderson Imbert, «Tres ejemplos de don Juan Manuel», Narraciones completas, vol. 1, Buenos Aires, Corregidor, 1990, págs. 604-10.

${ }^{10}$ Gracián, op. cit., págs. 720-21.

"Según recoge Diz, art. cit., pág. 292.

12 Ánderson Imbert, op. cit., pág. 607.

${ }^{13}$ Gracián, op. cit., pág. 721.

14 Azorín, op. cit., pág. 1127.

15 Ánderson Imbert, op. cit., pág. 607.
} 
trasentido, que quizá no se percibe porque la forma global ascendente se impone a la percepción de los detalles.

Frieiro, en cambio, cuenta que el deán de Santiago pasa a arzobispo del mismo lugar, y luego ocupa la sede de Tolosa; pero el narrador silencia qué cargo tiene allílí; en Tolosa recibe el personaje su capelo de cardenal, y después será elegido Papa. Frieiro no explica el papel de Tolosa, pero atenúa la dificultad que supone, al omitir el preciso título de obispo de esa sede.

Borges convierte la primera sede en episcopal y la segunda en archiepiscopal, de forma que el deán asciende a obispo de Santiago, arzobispo de Tolosa, cardenal y papa ${ }^{17}$. Es llamativo que sólo uno de los estudios sobre esta versión de Borges se detenga en esta modificación. González considera que «el afán de precisión y el gusto por la simetría» de Borges «se manifiestan en la gradación temporal y social de la carrera ascendente del deán», y le llevan «a alterar los datos literarios [...] e históricos (Deán de Santiago $\rightarrow$ Obispo de Santiago $\rightarrow$ Arzobispo de Tolosa $\rightarrow$ Cardenal Papa)» ${ }^{18}$. ¿Cómo se entiende este comentario en relación con don Juan Manuel? ¿Su relato es impreciso y está mal graduado, el autor tenía menos afán y gusto al componer?

En conclusión, las versiones examinadas muestran que la carrera del deán se percibe como ascendente no sólo en su conjunto, sino a cada paso; pero los cargos y sedes nombrados en el cuento pueden causar problemas. Si se dejan intactos, provocan al menos cierta perplejidad; parece haber un paso atrás en el ascenso, y llamarlo "promoción» es hacer violencia a los vocablos ${ }^{19}$. Ocultar los datos, e incluso modificarlos, como hace Borges, más parece imponer un sentido en el texto que entenderlo en sus propios términos ${ }^{20}$.

\footnotetext{
16 «Foi êle nomeado para a sé de Tolosa» (Frieiro, op. cit., pág. 64).

17 Las dos versiones de Borges presentan modificaciones de estilo, que no afectan al refundido de la carrera eclesiástica del personaje.

${ }^{18}$ González, art. cit., pág. 14 (cursiva original). También Devoto (op. cỉ,, pág. 393) menciona este cambio. Nada dicen Thomas Montgomery ( $($ Don Juan Manuel's tale of Don Illán and its revision by Jorge Luis Borges», Hispania, 47, 1964, págs. 464-66), England (art. cit., que trata esta versión y la de Azorín en págs. 76-77) ni Diz (art. cit.), quienes examinan sobre todo aspectos de estilo; Diz añade una comparación entre las dos versiones borgianas.

19 Violencia que también aparece en algunos estudios: «cada entrada [de mensajeros] supone un escalón más en el ascenso jerárquico del Deán: Arzobispo đe Toledo [sic], Obispo de Tolosa, Cardenal, Papa», escribe Pedro L. Barcia (Análisis de "El conde Lucanor», Buenos Aires, Cen* tro Editor de América Latina, 1968, pág. 55), sin explicar en qué consiste el "escalón más» del obispado de Tolosa. Por lo demás, el mismo error de mencionar Toledo por Santiago se encuentra en Azorín (op. cit., pág. 1127).

20 Como señalan Knust (Juan Manuel, El libro..., ed. cit., pág. 330) y Devoto (op. cit., pág. 393), casi todos los editores y adaptadores mantienen los términos originales; sólo una versión moderna de El conde Lucanor (Madrid, Hemando, 1943) habla de «obispo de Santiago» y «arzobispo de Tolosa» (págs. 49, 50), como Borges. Lunardi edita «arzobispado de Santiago» y robispado de Tolosa», pero traduce el segundo como «arcivescovato» (El Conde Lucanor, ed. y trad. Emesto Lunardi, [Lugano], Cenobio, 1953, pág. 127).
} 


\section{EXPLICACIÓN: ¿POR QUE TOLOSA?}

Ha de reconocerse de antemano que un examen del ejemplo XI guiado por la pregunta sobre el obispado de Tolosa ofrece poco rendimiento. El texto es inequívoco al hablar de «arzobispado» en Santiago y «obispado» en Tolosa ${ }^{21}$. Es cierto que nada connota negativamente la marcha a Tolosa; si los acogieron bien en Santiago - «fueron muy bien recebidos et mucho onradamente» (pág. 55)-, igual hicieron en la nueva sede: «fueron muy bien recebidos de condes et de cuantos omnes buenos avía en la tierra» (pág. 56) ${ }^{22}$. Pero no se explica si el personaje gana algo con el cambio. Y, como dice don Juan Manuel en el Libro de los estados, «en pos del estado de los arçobispos es el estado de los obispos» ${ }^{23}$. Lo único que hace suponer que se trata de un ascenso es la cuidadosa estructuración y graduación del cuento, por los eventos y las actitudes, los periodos y los términos, que ha analizado England ${ }^{24}$.

Otra menuda divergencia entre las recensiones modernas y el texto medieval será la que proporcione una clave. ¿Dónde culmina la carrera eclesiástica del deán de Santiago? Los cinco modernos responden concordes: «Roma» ${ }^{25}$. En cambio, don Juan Manuel se guardó de utilizar este nombre: el deán hecho cardenal invitó a don Yllán a «que se fuese con él para la Corte», y don Yllán «consinti6 [...] et fuesse con él para la Corte», $y$ «fueron bien recebidos de los cardenales et de cuantos en la Corte eran», «et estando assí en la Corte, finó el Papa, et todos los cardenales esleyeron aquel cardenal por Papas (pág. 56). Los adaptadores podían considerar que estaban sustituyendo una antonomasia por el nombre propio; mas «Corte» era realmente el término propio en tiempos de don Juan Manuel. Desde finales del siglo XII, la corte papal pasaba largas temporadas en otras ciudades italianas, aunque tornaba a Roma; en 1305, Clemente V comenzó a tentar otras sedes, y en 1309 se estableció en Avignon,

\footnotetext{
${ }^{21}$ Dos copias del siglo XV (comúnmente llamadas «H» $\mathrm{y} « \mathrm{M} »$ ) ofrecen «arçobispado de Tolosa», pero son testimonios de poco valor para el establecimiento del texto (ver aparato de las ediciones críticas de Ayerbe-Chaux (Libro del Conde Lucanor, 1983, págs. 144.45; y de José Manuel Blecua (en Don Juan Manuel, Obras completas, vol. 2, Madrid, Gredos, 1983, págs. 106-07). Incluso Ayerbe-Chaux, que resta importancia al problema del ascenso en una nota de su edición crítica (pág. 144), mantiene «obispado de Tolosa» en su versión modernizada ( $L$ bro del Conde Lucanor, ed. Reinaldo Ayerbe-Chaux, Madrid, Alhambra, 1985, pág. 85).

22 En el texto cito por la siguiente edición: El conde Lucanor, ed. Guillermo Serés, estudio preliminar de Germán Orduna, Biblioteca Clásica 6, Barcelona, Crítica, 1994; doy entre paréntesis el número de página.

${ }^{23}$ Juan Manuel, El libro de los estados, ed. Ian R. Macpherson y Robert Brian Tate, Madrid, Castalia, 1991, libro II, cap. xlvi, pág. 369.

24 England, art. cit., págs. 74-77.

${ }^{25}$ Gracián, op. cit., pág. 722; Azorín, op. cit., pág. 1127; Borges, Historia universal..., pág. 305, y Antología.., pág. 221; Frieiro, op. cit., pág. 65; Ánderson Imbert, op. cit., pág. 607.
} 
donde continuaron sus sucesores hasta 1376, es decir, durante el tiempo en que se compuso y se leyó por primera vez El conde Lucanor. El texto es, por tanto, sensible a las vicisitudes de la historia eclesiástica contemporánea (y la repetición del término «corte» puede entenderse como una llamada de atención). Veamos entonces qué luz arroja ésta sobre la cuestión de Tolosa, para una interpretación más completa y rigurosa del cuento de don Yllán.

\section{LA PREGUNTA HISTÓRICA Y LA ALTERIDAD DEL EJEMPLO XI}

1. Sorprendentemente, al tiempo de escribirse El conde Lucanor Tolosa (Toulouse) era arzobispado ${ }^{26}$. Desde hacía poco tiempo: fue obispado sufragáneo de Narbona hasta 1317. ¿Por qué no utilizó don Juan Manuel ese nuevo rango, que habría dado mayor claridad a la carrera del deán? Sería una trivialidad pensar que no estaba informado ${ }^{27}$. Había motivos para preferir el obispado. En primer lugar, hablar de arzobispado de Tolosa traería el cuento a la contemporaneidad, en desacuerdo con el pasado impreciso de «contescí́ a un deán» y «avía un deán» en la presentación de la historia (pág. 53). Más aún: paradojicamente, el obispado de Tolosa era mejor que el arzobispado para significar un ascenso. El prelado de Tolosa había sido el más rico y poderoso del Mediodía de Francia, por la amplitud y opulencia de su territorio ${ }^{28}$. La conversión en arzobispado no consistió en extender su autoridad sobre otras diócesis ya existentes, sino en crear siete nuevas desmembrándolas de la antigua diócesis tolosana. Al antiguo obispado correspondían íntegramente 45.000 libras de renta que luego hubieron de dividirse en 10.000 para el arzobispado y 5.000 para cada diócesis sufragánea ${ }^{29}$. En consecuencia, el ascenso en rango canónico conllevó una disminución de influencia y recursos económicos. Lo oportuno para el cuento manuelino, por tanto, era el obispado, que aportaba las notas de antigüedad y extraordinaria riqueza.

2. El obispado de Tolosa era rico, pero no especialmente fácil de gobernar. Los condes soberanos de Tolosa -a los cuales parece aludir el cuento (pág. 56)- fueron grandes señores independientes hasta mediados del siglo XII, y en su tiempo el cargo de obispo era una pieza clave en las disputas

\footnotetext{
${ }^{26}$ Ya Knust (El libro..., pág. 330) notó que «Tolosa» se refería a Toulouse, no a la ciudad guipuzcoana, que nunca fue sede episcopal.

${ }^{27}$ Knust (ibidem) sugiere que la conversión de Toulouse en arzobispado implica 1317 como año ante quem para la acción relatada, «wenn man bei Johann Ennanuel in solchen Angaben geschichtliche Genauigkeit voraussetzen könnte». Más que la exactitud histórica, lo que importa es sur conciencia de la historia y de los acontecimientos contemporáneos, como se mostrará.

28 J.-M. Vidal, «Les origines de la province ecclesiastique de Toulouse (1295-1318)», Annales du Midi, 15, 1903, págs. $289+328$ y 469-92; y 16, 1904, págs. 5-30 (ver vol. 15, pág. 289).

${ }^{29}$ Ibidem, págs. $290,469,486$.
} 
de autoridad entre ellos y el Papa ${ }^{30}$. Los condes controlaban la elección del obispo; pero el Papa podía deponer a prelados que resistiesen demasiado a su autoridad, como hizo en 1178 y 1205; por otra parte, un conde intentó expulsar en 1211 a un obispo fiel al Papa. Sobre aquella diócesis fulminaron los Papas varios interdictos. ¿Qué ofrecía entonces Tolosa, para que representar un destino superior a Santiago e inmediatamente anterior al cardenalato?

3. Varias circunstancias podían ilustrar Tolosa a ojos de don Juan Manuel y sus contemporáneos. En la ciudad estudiaron santo Domingo y los primeros frailes predicadores; más tarde, el prestigioso studium de Tolosa contó con numerosos profesores dominicos ${ }^{31}$. Es conocido el aprecio de don Juan Manuel a esta orden religiosa, modelo en el uso de la lengua vernácula y en el cultivo del exemplum ${ }^{32}$.

Por otra parte, a finales del siglo XIII (1296-97) fue obispo de Tolosa Luis, hijo de Carlos II de Anjou, rey de Nápoles y conde de Provenza. El relieve de su figura creció a comienzos del siglo XIV, ya que su canonización tuvo lugar en $1317^{33}$. Además, podía ser bien conocido en la Península Ibérica porque estuvo como rehén en Tarragona y Barcelona; después resultó emparentado con la corte aragonesa, cuando su hermana Blanca se casó con Jaime II. Don Juan Manuel se casó con una hija de este matrimonio, sobrina de San Luis, por tanto ${ }^{34}$. Otro hijo de Jaime II y Blanca de Anjou, Juan de Aragón, fue eclesiástico y visitó Avignon en 1311; el Papa Juan XXII se tomó interés en su educación, y más adelante lo designó arzobispo de Toledo, cargo que dio lugar a una relación constante, a veces difícil, con su cuñado don Juan Manuel ${ }^{35}$.

Durante la residencia del papado en Avignon, Tolosa fue uno de los cinco obispados, junto con Avignon, Albi, Rouen y Auxerre, que proporcionaron tres cardenales; en su caso, todos durante la primera mitad del siglo ${ }^{36}$. En Tolosa, al servicio del obispo San Luis, residió Jacques Duèse de Cahors, más tarde

\footnotetext{
39. Laurent Mack, Les comtes de Toulouse et leur entourage, XIle-XIIle siècles: rivalites, alliances et jeux de pouvoir, Toulouse, Privat, 2000, págs. 340-44.

31 Jean-Luc Dejean, Les comtes de Toulouse, 1050-1250, Paris, Fayard, 1988, págs. 352-58.

${ }^{32}$ María Rosa Lida de Malkiel, "Tres notas sobre don Juan Manuel», Estudios de literatura espar̃ola y comparada, Buenos Aires, EUDEBA, 1966, págs. 92-133 (especialmente págs. 94-95),

${ }^{33}$ «Vita S. Ludovici episcopi Tolosani», Analecta Bollandiana, 9, 1890, págs. 278-353 (especialmente págs. 339-40).

${ }^{34}$ Andrés Giménez Soler, Don Juan Manuel: biografía y estudio crítico, Zaragoza, Tip. «La Académica", 1932, págs. 49, 72-73.

35 J. Ernesto Martínez Ferrando, Jaime II de Aragon: su vida familiar, vol. 1, Barcelona, Escuela de Estudios Medievales, 1948, págs. 141-51; R. B. Tate, «The infante don Juan de Aragon and Don Juan Manuel», Juan Manuel Studies, ed. Ian Macpherson, London, Tamesis, 1977, págs. 169-79.

${ }^{36}$ Bernard Guillemain, La Cour pontificale d'Avignon (1309-1376): Étude d'une société, Paris, Boccard, 1962, pág. 207.
} 
Papa con el nombre de Juan XXII ${ }^{37}$. En la segunda mitad del siglo accedieron al sumo pontificado dos eclesiásticos que habían estudiado y enseñado en el studium de Tolosa, Inocencio VI y Urbano V, de forma que lectores de la generación siguiente a don Juan Manuel podían seguir percibiendo una relación entre esa ciudad y el papado ${ }^{38}$.

4. Pero el ápice de esa relación tuvo lugar ciertamente en tiempos de Juan XXII (1316-1334), es decir, durante la escritura de El conde Lucanor. En 1317 se condenó a Hugues Géraud, obispo de Cahors, por intento de asesinato y maleficio contra el Papa; el proceso implicó a Gailhard de Pressac, obispo de Tolosa ${ }^{39}$. Este era un personaje poco escrupuloso, que había provocado un fuerte endeudamiento de su diócesis. Según algunas declaraciones en el proceso, Gailhard presumía de que tuvo al alcance de la mano ser elegido papa en el cónclave de 1316, que se decantó finalmente por Jacques Duèse. También se dijo que él prestó una capilla para el maleficio contra Juan XXII, e incluso se encargó personalmente de supervisar la ceremonia. Asimismo, contaba con llegar al sumo pontificado una vez que triunfase la conjura. Pero todo se descubrió, y Hugues Géraud murió en el suplicio; Gailhard fue depuesto de Tolosa, y se le ofreció un cargo de provisión muy inferior, que él desdeñó. Inmediatamente después se produjo la elevación de Tolosa a archidiócesis con la desmembración de su territorio. Juan XXI designó para aquella sede a un hombre de su confianza, Jean de Comminges, a quien hizo cardenal en 1327; además, Guillemain observa: «on peut remarquer que la prédilection de Jean XXII se porta sur la provice de Toulouse qu'il avait créée et dont il tira quatre cardinaux ${ }^{40}$. El más importante de ellos fue el mencionado Jean de Comminges, quien contaba, según cierta versión, con suficientes votos para ser elegido papa en el cónclave de 1334, pero perdió el favor de los cardenales porque no se comprometía a mantener la corte fuera de Roma. La elección recayó entonces sobre Jean Fournier -Benedicto XII (1334-1342)-, que era originario de Saverdun, cerca de Tolosa, y tuvo de 1317 a 1326 el cargo de obispo de Pamiers, una de las diócesis desmembradas del antiguo obispado tolosano ${ }^{4 l}$.

5. Probablemente, el deán de Santiago, su interés por la nigromancia y su carrera están modelados sobre personajes históricos. Uno de ellos es Gailhard de Pressac, obispo de Tolosa con aspiraciones al papado, que utilizó maleficios contra Juan XXII, fue descubierto y perdió su cargo. Otro es Jean de Commin-

\footnotetext{
${ }^{37}$ Ibidem, pág. 121.

38 Ibídem, pág. 118; G. Mollat, Les Papes d'Avignon (1305-1378), 10" ed., Paris, Letouzey te Ané, 1965, págs. 106, 117.

39 Vidal, art. cit, vol. 15, págs. 471-82; Mollat, op. citt., págs. 43-45.

40 Ver Vidal, art. cit., vol. 15, pág. 485; Guillemain, op. cit., pág. 202; la cita es de pág. 207.

${ }^{41}$ Guillemain, op. cit., pág. 240; Mollat, op. cit., págs. 72-73.
} 
ges, arzobispo de Tolosa y cardenal que pudo, según se dijo, haber llegado a papa. Otro posible modelo es el mismo Juan XXII, quien pasó por Tolosa y recibió el cardenalato siendo, por breve tiempo, obispo de una diócesis del occidente peninsular (Oporto, en 1313). Un rasgo de su pontificado fue el nepotismo que ejerció repartiendo a familiares y compatriotas bienes temporales, oficios seglares y nombramientos de obispos y cardenales ${ }^{42}$, como el deán que va cediendo los puestos vacantes a «un su hermano», «un su tío, hermano de su padre», y «un su tío, herrnano de su madre, que era omne bueno anciano» (págs. 55-56) ${ }^{43}$. Juan XXII fue acusado por sus enemigos de superstición y creencias mágicas, y de herejía; por otra parte, es cierto que combatió a los hechiceros y a los herejes y cismáticos ${ }^{44}$, como el deán hecho papa, que despide a don Ylián con cajas destempladas, «diziéndole que si más le affincasse, quel faría echar en una cárcel, que era ereje et encantador, que bien sabía que non avía otra vida nin otro oficio en Toledo, do él morava, sinon vivir por aquella arte de nigromancia»" (pág. 57). Quizá también sea pertinente para el ejemplo XI el recuerdo de Pedro Hispano, deán de Lisboa, arzobispo de Braga, y brevemente Papa con el nombre de Juan XXI (1276-77); se dedic6 toda su vida al trabajo intelectual - filosofía, medicina, astronomía- y por ello fue injustamente acusado de afición a la magia ${ }^{45}$. Parece claro que el cuento del deán de Santiago, aun con ser fantástico, levanta acta de comportamientos e intereses reales en el mundo contemporáneo.

6. Sobre las otras dos ubicaciones del cuento, Toledo y Santiago, ya se han pronunciado investigaciones anteriores. Toledo tenía una larga fama de relación con la ciencia mágica ${ }^{46}$. La pugna entre el mago de Toledo y el deán de

\footnotetext{
42 Juan XXII nombró a veintiocho cardenales, de los cuales veintitrés fueron franceses, y muchos parientes suyos, por lo cual se habla del comienzo de un «nepotismo a gran escala» (Paredes, Javier [dir.], Maximiliano Barrio, Domingo Ramos-Lisson y Luis Suárez, Diccionario de los Papas y concilios, Barcelona, Ariel, 1998, pág. 247; ver también Mollat, op. cit., pág. 59). Esta práctica podía ser bien conocida por la aristocracia española, y en particular por don Juan Manuel, pues su suegro Jaime II de Aragón vio frustrado el deseo de que su hijo Juan recibiese el cardenalato; el Papa le contestó que no era cargo apropiado para una persona de linaje real (Martínez Ferrando, op. cit., pág. 151). Por otra parte, la política de Juan XXII o de sus legados no favoreció a don Juan Manuel, y en alguna ocasión lo perjudicó (ver Giménez, op. cit., págs. 70-73; Reinaldo Ayerbe-Chaux, Yo, don Juan Manuel: apologia de una vida Madison, Hisparic Seminary of Medieval Studies, 1993, págs. 133-34). También contraríó a Jaime II de Aragón en las disputas por el reino de Mallorca (Mollat, op. cit., págs. 442-45); las misiones diplomáticas aragonesas procuraron congraciarse precisamente con Jean de Conminges (Guillemain, op. cit., pág. 238).

${ }^{43} \mathrm{El}$ nepotismo ya aparece en una de las posibles fuentes del ejemplo XI (recogida en Ayerbe-Chaux, «El Conde..., pág. 240), pero su desarrollo por don Juan Manuel indudablemente producía una semejanza entre el personaje literario y el Papa contemporáneo.

${ }_{44}$ Guillemain, op. cit., págs. 130-34; Mollat, op. cit., págs. 47-49, 51, 54-57.

${ }_{45}$ Horace K. Mann, The Lives of the Popes in the Middle Ages, vol. 16, London, Kegan Paul, Trench, Trubner \& Co, 1932, págs. 54-56.

46 Ver Knust, El libro..., págs. 327-29, y Ayerte-Chaux, «El Conde..., págs. 103-04, 243-46.
} 
Santiago puede representar la existente entre esas dos sedes archiepiscopales, que se decantaba a favor de Toledo ya el siglo XIII ${ }^{47}$; Miranda considera que el deán deseoso de adquirir la nigromancia podría tener planes de resucitar la decaída sede gallega, y que su conquista del sumo pontificado evoca y parodia el esplendor y poder que logró el arzobispo Diego Gelmírez en la primera mitad del siglo XII. Ha de mencionarse, además, que un arzobispo de Santiago a finales del XIII recibió el sobrenombre de «nigromántico»; y que en 1318 el prelado que nombró Juan XXII, Berenguer de Landorre, de origen provenzal y antiguo profesor de Tolosa, tuvo grandes problemas para tomar posesión de aquella sede: incluso necesitó levar tropas para poner sitio a Santiago, y después de haber entrado sufrí nuevos combates y fue expulsado de la ciudad ${ }^{48}$. Añádase que entre 1310 y 1341 no hubo un solo cardenal español ${ }^{49}$, y el ejemplo XI resulta aún más dislocado: un deán y arzobispo de Santiago llega fácil y como mágicamente a la más rica diócesis ultrapirenaica, al cardenalato y al sumo pontificado; mientras en la realidad, la sede gallega costó duros combates a un arzobispo francés designado por un Papa que no había nombrado cardenal a ningún español. En este aspecto, pues, don Juan Manuel ofrece una inversión lúdica de la historia.

Con estos datos, se puede entender mejor el ejemplo XI en su carácter de respuesta a determinadas cuestiones. Resultaría trivial considerarlo meramente respuesta a la pregunta del conde Lucanor a Patronio: ¿qué hacer con aquel hombre que pide su ayuda, pero nunca le asiste cuando lo necesita? (págs. 52-53). A eso ya contesta cualquiera de los ejemplos, mucho más breves, que son posibles fuentes y paralelos del texto manuelino ${ }^{50}$.

Don Juan Manuel emprende una construcción más compleja y sutil, según se aprecia comparándolo precisamente con esos sencillísimos ejemplos. Ayerbe-Chaux considera que los más cercanos son los de Étienne de Bourbon y la Scala Coeli ${ }^{51}$. El primero refiere:

Cierto gran maestro en literatura tenía un discípulo de noble alcurnia el cual con frecuencia decía ante el maestro que los obispos de Francia eran ciegos porque no llamaban para una prebenda eclesiástica a su maestro, tan buen clérigo. Cuando lo hicieron obispo al discípulo, llamó a sus sobrinos para los beneficios eclesiásticos, ignorando al maestro ${ }^{52}$.

${ }^{47}$ Miranda, art. cit., págs. 330-31.

48 Vicente de la Fuente, Historia eclesiástica de España, $2^{\text {a }}$ ed., vol. 4, Madrid, Compañía de Impresores y Libreros del Reino, 1873, págs. 350-54.

${ }^{49}$ Guillemain, op. cit., pág. 190.

${ }^{50}$ Recoge los textos Ayerbe-Chaux, «El Conde.... págs. 239-43.

sI Ibrdem, págs. 99-100.

32 Ibtdem, pág. 240. 
Sigue un desengaño que nada tiene que ver con la magia. La Scala Coeli sí presenta un mago:

Cierto hombre tuvo un discípulo muy amado a quien había obligado a gratitud con las muchas enseñanzas y servicios. Dijo el discípulo al maestro: «Si fuera rico, os haría infinitos beneficios». Para probarlo, el maestro le hizo sentir por medio de cierta magia que era emperador y el maestro le rogaba que cumpliese lo prometido porque muchos beneficios estaban vacantes. Pero el discípulo negaba conocerlo y le dijo el maestro: «Yo soy aquel que os dio todo esto y he aquí que ahora os lo quito todo». Y, desaparecido el encanto, quedó desnudo ${ }^{53}$.

Don Juan Manuel presenta una historia clerical, como Étienne de Bourbon, y lleva al personaje hasta el máximo ascenso, como la Scala Coeli. Pero este ascenso se presenta graduado en cuatro pasos concretos. Ya se ha mostrado que el obispado de Tolosa supone un avance desde el arzobispado de Santiago, considerando la decadencia de la sede gallega en el siglo XIV, frente al esplendor y riqueza de Tolosa hasta 1317, más la buena conexión con el papado en tiempos de Juan XXII; es decir, implica un progreso no s6́lo en términos absolutos, sino también en vista del punto culminante que alcanzará la carrera del deán. La concreción de las sedes añade, por tanto, verosimilitud a lo narrado: tan natural es que un deán de Santiago - bien relacionado familiarmente, cual es el caso- sea elegido arzobispo de la misma sede, como que un eclesiástico radicado en Tolosa acceda al cardenalato e incluso al papado. El único capricho en este devenir es precisamente el paso de Santiago a Tolosa; pero resulta menos chocante porque mantiene el rango jerárquico o incluso retrocede aparentemente, y además ocupa un lugar poco prominente en la serie, no siendo el primero ni el último. El ejemplo manuelino también se distingue de los dos textos citados por la concreción de los favores negados al maestro (las sedes que van quedando vacantes) y de los beneficiarios de ellos (los familiares del deán individualizados en cada caso); más «los detalles locales», «la evocación miniaturista de la cámara del nigromante» e incluso la elección del nombre de este ${ }^{54}$.

Graduación, concreción, verosimilitud son, por tanto, rasgos característicos del ejemplo xI; y son propios de la «forma simple» que André Jolles llama «memorabile». Según Jolles, está es la forma en que naturalmente se presenta

${ }^{\text {s3 }}$ Ibrdem, pág. 242.

${ }^{54}$ Las citas proceden de Ayerbe-Chaux, «El Conde..., pág. 103; y Lida, op. cit., págs. 11011. José Amador de los Ríos (Historia crítica de la literatura española, vol. 4, reimpr. Madrid, Gredos, 1969, pág. 280) sefialó la importancia del apellido «Illán» en la ciudad de Toledo y la fama de nigromancia que lo acompañaba; Krust (El libro..., págs. 324-27) discute esos datos, pero Ayerbe-Chaux vuelve sobre la cuestión y concluye que es «un nombre íntimamente ligado a la famosa ciudad» ( $₫ E l$ Conde..., págs. 102-03), aunque no se comprueben todas las referencias de Amador. 
lo real fáctico en toda su singularidad y significatividad; y también configura los relatos imaginarios que pretenden gozar del mismo crédito ${ }^{55}$.

Sin embargo, la verosimilitud del ejemplo se esfuma en el mismo momento en que don Yllán despoja al ingrato de sus fingidos honores. ¿De qué sirve, entonces? En primer lugar, caracteriza la habilidad del gran maestro, que ha trazado la fantástica carrera de la forma más conveniente para que el otro la tuviese por real; y también la habilidad de don Juan Manuel frente al lector, pues tampoco éste sabe que está contemplando una ilusión hasta que el final la revoca; según comenta Serés en su edición:

el autor dispone el relato de tal forma, que, análogamente a cómo el nigromante don Ilán juega con el deán para demostrar su ingratitud, don Juan Manuel lo hace con el lector, pues no le advierte en ningún momento de que también le ha integrado en el tiempo ilusorio del deán; de igual modo juega Patronio con el conde Lucanor (pág. 53).

Así pues, el lector cree que le están contando una historia, y al final se encuentra con que le han contado otra; es más, parece que está ante un tipo de relato, el «memorabile», y se encuentra con otro donde se encuentra naturalizado lo maravilloso: el «cuento de hadas» («Märchen»). Hay en el ejemplo XI otro rasgo propio de esta forma, según la describe Jolles: la contraposición con aquello que solemos considerar el modo corriente de suceder las cosas en el mundo ${ }^{56}$. Contraposición incluso en los detalles: la influencia eclesiástica no discurria de Santiago hasta la corte papal con facilidad, sino en sentido inverso y con grandes dificultades; y si en el siglo XIV accedieron al papado varios eclesiásticos vinculados con Tolosa, el caso es que precisamente dos prelados de esa sede vieron frustradas sus posibilidades. La mayor contraposición con el mundo real y la mayor maravilla son, evidentemente, que la ingratitud sea castigada incluso en un poderoso; de manera que se satisface lo que Jolles llama «un impulso moral ingenuo» que determina la forma «cuento de hadas» ${ }^{57}$.

Desde aquí se puede volver a la concreción y verosimilitud que emparentan el ejemplo XI con el «memorabile». Lo castigado en él, además de la ingratitud, es todo aquello que la concreción ha aportado: la ambición personal dentro de la Iglesia, el recurso a la magia para satisfacerla, el nepotismo de los poderosos. La realidad de estos males se subraya por la acumulación de detalles, y en especial porque se ubican en Santiago y Tolosa, dos sedes donde realmente se habían desplegado las mismas ambiciones y los mismos procedimientos. No obstante, el ejemplo XI no es un mero ejercicio de crítica; al con-

\footnotetext{
s5 André Jolles, Einfache Formen, 24 ed., Halle, Max Niemeyer, 1956, págs. 173-80.

56 Ibidem, pág. 201.

57 Ibidem, pág. 200-03.
} 
figurar la carrera eclesiástica de manera señaladamente inversa a lo normal en el mundo contemporáneo, y al encerrarla en los confines de un encantamiento que primero la produce y después la aniquila como castigo, manifiesta también un distanciamiento lúdico.

El cuento de don Yllán es, en fin, una respuesta al entomo histórico y a un reto de carácter literario. En primer lugar, se enfrenta con las tensiones producidas por la situación de la Iglesia y el comportamiento de ciertos eclesiásticos. Las tensiones entre eclesiásticos y nobles son generales en el siglo $\mathrm{XIV}^{58}$, y para don Juan Manuel se manifiestan en la oposición del legado papal a sus aspiraciones a la tutoría del rey menor de edad, y en sus largas y cambiantes relaciones con su cuñado el arzobispo de Toledo; estas incluyeron el difícil episodio de Diego García, vasallo del arzobispo asesinado por don Juan Manuel en 1321 porque se oponía a sus aspiraciones políticas. Ahora bien, tales choques no sólo contrariaban las ambiciones del aristócrata, sino que también abrían un conflicto con convicciones sustentadoras del mundo medieval. Como explica él mismo en el Libro del cavallero et del escudero:

tengo que el más alto estado es el clérigo missacantano [...]: et quanto el clérigo missacantano á mayor dignidat, así commo obispo o arçobispo o cardenal o Papa, tanto es el estado más alto, por que puede fazer obras de que aya mayor mereçicimiento, et aprovechar más al pueblo en lo spiritual et en lo tenporal ${ }^{59}$.

Una crítica y burla de situaciones, personajes y ambiciones eclesiásticos que evitase la colisión abierta con estas ideas - no sólo generales, sino también propias de don Juan Manuel-exigía la mezcla de la realidad y lo maravilloso lograda en el ejemplo XI ${ }^{60}$. Esta es la segunda cuestión a que responde

${ }^{58}$ David A. Flory, "El Conde Lucanor»: don Juan Manuel en su contexto histórico, Madrid, Pliegos, 1995, págs. 44-49.

${ }^{99}$ Don Juan Manuel, «Libro del cavallero et el escuderon, Cinco tratados, ed. Reinaldo AyerbeChaux, Madison, Hispanic Seminary of Medieval Studies, 1989, págs. 7-88 (cita de pág. 12).

60 En el Libro de los estados, don Juan Manuel reitera que el estado mejor de la clerecía es el del papa (ed. cit, libro II, cap. xxxv, págs. 344-45); los capítulos dedicados a los posibles desmerecimientos del papa los plantea de manera teórica y general (libro II, caps. xxxvii-xli, págs. 351-60). También se distancia de los problemas relacionados con el poder político del papa: «a muy grant poder en lo tenporal. Mas quál o quánto es este poder, porque yo só de Castiella, et los reys de Castiella et sus reinos [son] más sin ninguna subgectión que otra tierra del mundo, por ende no sé yo mucho desto. Mas los que son del Imperio, o a los que esto tañe, ellos se lo vean; ca nós non avemos que adobar en esto, nin nos queremos meter en lo que non avemos que librars (libro II, caps. xxxvi, pág. 348). Por otra parte, Palafox cuenta el ejemplo XI entre los que ejercen una crítica oblicua en El conde Lucanor, porque «tienen como protagonistas a sendos poderosos necios, ignorantes, ineptos e incluso soberbios: como si se quisera probar y reiterar la idea de que son ellos los que necesitan las más grandes lecciones» (Eloísa Palafox, «Las fábulas del poder: una lectura de El conde Lucador», Discursos y representaciones en la Edad Media, ed. Concepción Company, Aurelio González y Lillian von der Walde, México, Universidad Nacional Autónoma de México, 1999, págs. 259-70, cita de pág. 262). 
el texto: cómo combinar con éxito varias formas diferentes. En primer lugar, juega con la forma que representa con toda concreción la facticidad del mundo real («memorabile») y la que ofrece una contraposición imaginaria al mundo real («cuento de hadas»). En términos del sistema medieval de géneros, se trata de una indagación en los límites intemos del exemplum. Pues el exemplum admite una gran variedad de materias tomadas de la realidad y la fantasía: «leyendas, cuentos orientales, relatos milagrosos, fábulas antiguas, anécdotas, relatos bíblicos, parábolas, observaciones de la historia natural, narraciones mitológicas, etc.» ${ }^{61}$; mas en sentido estricto se oponen el exemplum que narra un hecho auténtico, un precedente tomado de la historia, y la fabula, narración de un caso fingido para ilustrar una ley moral o un consejo astuto; y estos dos, como subgéneros didácticos, se distinguen del cuento que provoca el placer y la evasión de la seriedad cotidiana mediante lo maravilloso ${ }^{62}$. Por esos tres temenos se mueve el relato de don Yllán y el deán de Santiago, con su ubicación precisa en el espacio e imprecisa en el tiempo, su riqueza en detalles y su esquematismo estructural, su semejanza junto con su diferencia respecto de acontecimientos contemporáneos, y por último con la repentina y efectista intervención de la magia.

\section{CONCLUSIONES}

1. La indagación de la historia, desencadenada por lo enigmático del «obispado de Tolosa», permite comprender mejor la constitución y los sentidos del ejemplo XI de El conde Lucanor. Asegura, pues, la identidad del texto o, desde otro punto de vista, su alteridad respecto de los lectores modernos. Resulta ser todo un experimento literario para salvar los límites entre los géneros realistas y fantásticos, algo que difícilmente percibe quien no conoce su relación con los sucesos de su tiempo. También es una toma de postura frente a las tensiones del momento, en una clave a la par crítica y distanciada. El lector actual no compartirá las inquietudes de don Juan Manuel, y estará tentado de tener este sentido por prescindible; pero puede apreciarlo como creación imaginativa de un mundo que imita la realidad y a la vez la invierte, como hacen Quevedo en los Sueños y Swift en los Viajes de Gulliver. Se puede añadir el ejemplo XI a los casos de «humor tendencioso» que estudia Kaplan en El conde Lucanor, y percibir mejor una dimensión lúdica y satírica en la obra. También se puede sumar, mutatis mutandis, a «los cuentos de carácter histórico» donde «Juan Manuel presenta una visión distorsionada de la historia, casi un

${ }^{61}$ María Dolores Nieto, Estructura y función de los relatos medievales, Madrid, CSIC, 1993, pág. 7.

62 Jauss, Alterität..., anexo a págs. 46-47; Nieto, op. cit., págs. 4-5. 
mundo al revés cuya coherencia procede de la lógica de su ficción, más aún, de la lógica del carnaval» ${ }^{63}$. Este autor, que tantas veces se reduce al didacticismo y la defensa del estatus de la aristocracia y del suyo personal, también da algunos tonos semejantes a los de aquel su contemporáneo que compuso el Libro de buen amor ${ }^{64}$.

2. La historia de la recepción del cuento de don Yllán muestra cómo se ha desconectado de su propio tiempo y queda asimilado al horizonte del lector. La forma en que muchos sustituyen «corte» por «Roma» es un síntoma de que no tienen en cuenta el mundo en que se produjo y leyó por primera vez el texto. Los sucesivos lectores se han ido viendo a sí mismos: Gracián destacó el ingenio y la moralidad ${ }^{65}$; Azorín eliminó buena parte de lo maravilloso y desarrolló la psicología de los personajes; Borges y Ánderson se ocuparon del rigor en la construcción, de la mezcla de realidad y fantasía y del juego con el tiempo ${ }^{66}$. Los mismos intereses se manifiestan en los estudios del cuento, mientras que la historia se ha descuidado ${ }^{67}$. Se ha cerrado en falso la cuestión del obispado, o incluso se ha modificado el texto, haciéndola irrecuperable; y esto pri-

${ }^{63}$ Carmen Benito-Vessels, Juan Manuel: escritura y recreación de la historia, Madison, Hispanic Seminary of Medieval Studies, 1994, pág. 112.

64 Ian Macpherson muestra que el didacticismo de El conde Lucanor está pensado para el aristócrata cristiano medieval, y por eso, considera, ha quedado obsoleto ( $₫$ Dios y el mundo: The Didacticism of El Conde Lucanom, Romance Philology, 24, 1970-71, págs. 26-38; especialmente págs. 37-38); siguiendo esa interpretación, Dayle Seidenspinner-Núñez contrapone El conde Lucanor, obra didáctica y rígida, al Libro de buen amor, donde reinan la inestabilidad y el juego ("On 'Dios y el mundo': Author and Reader Response in Juan Ruiz and Juan Manuel», Romance Philology, 42, 1988-89, págs. 251-66). En cambio, L. de Looze («Subversion of meaning in Part I of El Conde Lucanom, Revista Canadiense de Estudios Hispánicos, 19.2, 1995, págs. 12954) y Jonathan Burgoyne ("Ideology in action: The consequences of paradox in El conde Lucanor, part I $»$, La Corónica, 30.1, 2001, págs. 37-65) señalan cierta apertura del sentido en la obra de don Juan Manuel, por las inevitables ambiguiedades inherentes a la complejidad del mensaje didáctico que pretende transmitir el autor. Gregory B. Kaplan señala la multiplicidad de sentidos lograda por la elaboración humorística del texto («Innovation and Humor in Three of $E t$ Conde Lucanor's Most Amusing Exemplos: A Freudian Approach», Hispanofila, 123, 1998, págs. 1-15), postura más cercana a la de este artículo. Sobre la inestabilidad del mundo que representa El conde Lucanor, un caos de contingencias variables que más tarde aparecería como «el mundo al revés», ver también Peter N. Dunn, «The Structures of Didacticism: Private Myths and Public Fictions", Juan Manuel Studies, ed. Ian Macpherson, London, Tamesis, 1977, págs. 53-67; y «Don Juan Manuel, The World as Text», $M L N, 106.2$, 1991, págs. 223-40.

65 Según el estudio de Christine Orobitg («Gracián, lector de Don Juan Manuel a través de Argote de Molina», Criticón, 56, 1992, págs. 117-33), Gracián se sintí atraído por El conde Lucanor porque reconocía en él actitudes éticas y estéticas propias, como el didacticismo y el pesimismo.

${ }^{66}$ Ver Devoto, op. cit., págs. 388, 393; England, art. cit., págs. 76-77; González, art. cit.; Diz, art. cit., pág. 291.

${ }^{67}$ Mucino reser̃a tres tipos de interpretaciones del ejemplo Xl: moral, fantástica y esotérica; propone recuperar un sentido histórico, que él planta en términos de didacticismo político en general (art. cit., págs. 261, 264-65). 
va a los lectores de percibir un empeño formal, ético e histórico de mayor alcance. Las versiones modemas son una vía de acceso al cuento medieval, pero es preciso llegar a éste y explorarlo en todas sus dimensiones, más allá de los límites que, paradojicamente, le imponen sus admiradores.

El presente estudio tiene, pues, un corolario para las futuras ediciones de El conde Lucanor: si se refieren a las versiones por Gracián, Azorín, Borges y Ánderson ${ }^{68}$, también será conveniente que incluyan una nota sobre el obispado de Tolosa y sus implicaciones para la estructura y el sentido de la peripecia del deán de Santiago.

${ }^{68}$ Como hacen, por ejemplo, la edición de Serés que utilizo (pág. 355), y también la de José Manuel Blecua (El conde Lucanor, Clásicos Castalia 9, Madrid, Castalia, 1969, pág. 93) y la de Alfonso I. Sotelo (Libro de los enxiemplos del Conde Lucanor e de Patronio, Letras Hispánicas 53, $2^{2}$ ed., Madrid, Cátedra, 1977, págs. 115-16). 